\title{
Peroxisomal Proliferation in Heart and Liver of Mice Receiving Chlorpromazine, Ethyl 2(5(4- Chlorophenyl)Pentyl) Oxiran-2-Carboxylic Acid or High Fat Diet: A Biochemical and Morphometrical Comparative Study
}

\author{
JOSEPH VAMECQ, FRANK ROELS, CHRISTIANE VAN DEN BRANDEN, AND JEAN- \\ PIERRE DRAYE \\ Laboratoire de Chimie Physiologique, University of Louvain and International Institute of Cellular and \\ Molecular Pathology [J.V., J-P.D.]; Menselijke Anatomie, Vrije Universiteit Brussel [F.R., C.vdB.]; and \\ Department of Pediatric Neurology, University of Louvain, [J-P.D.] Brussels Belgium
}

\begin{abstract}
Chlorpromazine and related drugs including trifluoperazine, clopenthixol, and fluphenazine are in vitro inhibitors of mitochondrial carnitine palmitoyltransferase and cytochrome $c$ oxidase and of peroxisomal carnitine octanoyltransferase from mouse heart and liver. By contrast with $0.1 \%$ ethyl 2(5(4-chlorophenyl)pentyl) oxiran2-carboxylic acid or $0.1 \%$ clofibrate-containing diets, the treatment of mice with $0.1 \%$ chlorpromazine-containing diet fails to induce peroxisomal proliferation in liver and heart. An $0.5 \%$ chlorpromazine-containing diet did induce peroxisomal proliferation. Inhibition of peroxisomal $\beta$ oxidation presumably via the reduction of carnitine octanoyltransferase by chlorpromazine elicits the appearance in liver of lamellar structures resembling those seen in human peroxisomal disorders and induces accumulation of very long-chain fatty acids in plasma. The peroxisomal proliferation induced by administration of high dose chlorpromazine is ascribed to its ability to depress mitochondrial fatty acid oxidation by impairing cytochrome c oxidase and carnitine palmitoyltransferase activities. (Pediatr Res 22: 748-754, 1987)
\end{abstract}

Abbreviations

DAB, 3,3'-diaminobenzidine

POCA, ethyl 2(5(4-chlorophenyl)pentyl) oxiran-2-carboxylic acid

Experiments with chlorpromazine, an inhibitor of peroxisomal carnitine octanoyltransferase, have led to the proposal that peroxisomal $\beta$-oxidation which was depressed by the phenothiazine in isolated hepatocytes (1) was dependent on carnitine (2). On the other hand, the inhibition of both cytochrome c oxidase and chlorpromazine palmitoyltransferase activities (2) were proposed as the cause of the reduced ketone body formation from long-

Received March 12, 1987; accepted August 14, 1987

Correspondence Joseph Vamecq, UCL 75.39, 75 Avenue Hippocrate, 1200 Brussels, Belgium.

Supported by Grants of the Belgian NFWO, FNRS, and SPPS, by Grant 84/9074 of the "Action de Recherche Concertée des Services du Premier Ministre", U.S Public Health Services Grant AM9235, European Communities Twinning Research Program, and Grant 3.0071 .83 of the Belgian FGWO. J.V. is Charge of the Belgian FNRS. chain fatty acids (1) in isolated hepatocytes incubated in the presence of chlorpromazine at concentrations between 0.4 to 1.0 $\mathrm{mM}$.

In several circumstances, in vivo inhibition of mitochondrial fatty acid oxidation in rodents is associated with peroxisomal proliferation. The latter phenomenon mainly consists of an increased peroxisomal population and enhanced capacity of the peroxisomal $\beta$-oxidation. One example is treatment of rodents with 2-oxiran carboxylic acid derivatives such as POCA which are well-known inhibitors of hepatic carnitine palmitoyltransferase type I and which produce a peroxisomal proliferation in liver (3). Another example is given by treatment of mice with valproic acid $(4,5)$.

Chlorpromazine, unlike 2-oxiran carboxylates, has been reported to produce lipid accumulation but no induction of peroxisomal proliferation in rodent livers (6). This discrepancy between the in vitro property of chlorpromazine to inhibit mitochondrial fatty acid oxidation and the failure of the drug to increase, in vivo, the peroxisomal population and $\beta$-oxidation capacity is only apparent. Indeed, we demonstrate that a diet containing $0.5 \%(\mathrm{w} / \mathrm{w})$ chlorpromazine causes peroxisomal proliferation in liver and heart. On the other hand, we report that the diet containing only $0.1 \%(\mathrm{w} / \mathrm{w})$ chlorpromazine is unable to induce peroxisomal proliferation and we cannot conclude that this drug concentration inhibits mitochondrial fatty acid oxidation in vivo. In the treated animals, impairment of peroxisomal fatty acid oxidation could occur as attested by a lipid deposition in liver cells mimicking the storage of very long-chain fatty acids in tissues from patients with peroxisomal disorders and by the accumulation of the very long-chain substrates in plasma. The effects of the administration to mice of the chlorpromazinecontaining diets are compared with those of a $0.1 \%(w / w)$ POCA and high fat [20\% oleate-(w/w)] diets.

\section{MATERIALS AND METHODS}

Adult male NMRI mice, weighing at least $28 \mathrm{~g}$, were used. Control mice were fed on a standard animal food. Treated animals were fed on a diet obtained by mixing the powdered animal food with either $0.1 \%$ clofibric acid, $0.1 \%$ POCA, $20 \%$ oleate, and 0.1 or $0.5 \%$ chlorpromazine.

Clofibric acid (2-5p(chlorophenoxy)-2-methylpropionic acid), trifluoperazine, homovanillic acid, and peroxidase type II were purchased from Sigma Chemical Co. (St. Louis, MO). The CoA derivatives of palmitic, lauric, octanoic, hexanoic, and acetic 


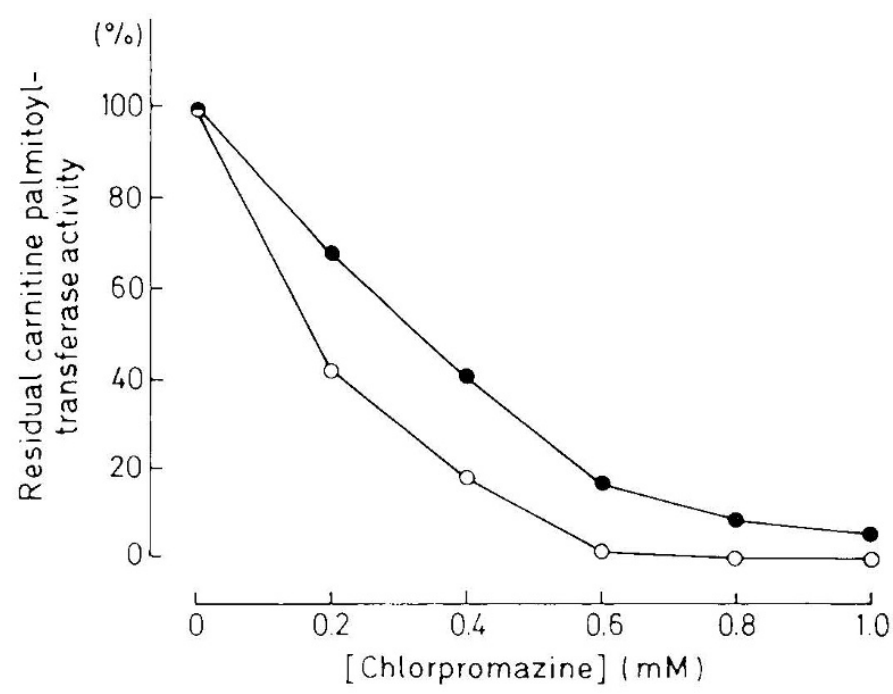

lig. I. Effect of chlorpromarine on the reaction catalyzed by carnitine palmitoyltransferase and monitored in mouse heart $(O)$ and liver

(-) homogenates. The activities are expressed as the percentage of the activity measured in the absence of chlorpromazine. acids were from Pharmacia (Uppsala. Sweden): FI). NAI) were from Boerhinger Pharma (Mannheim. FRG) and other common chemicals were of analvtical grade from Merck (I)armstadt. FR(i).

(hlorpromazine was kindly offered by Professor (i. L ambert (Department of Pharmacology. University of I ouvain. I ouvain. Belgium). Fluphenazine and clopenthixol were gifts from I abaz (Brussels. Belgium) and I.undbeck (Brussels. Belgium). respectively. POCA was generously given by I)r. (i. I udwig of BYK Gulden Lomberg Chemische Fabrick (imbl (Konstany. IRR(i).

Previously established procedures were used for the assay of the enzymes: palmitoyl-CoA oxidase. lauroyl-Co.A oxidase and glycolate oxidase (7), carnitine acyltransferases (8). cytochrome c oxidase (9). catalase and urate oxidase (10), and butyry-(0). dehydrogenase (11). The eyanide-insensitive lauroy-CoA oxidation was measured according to Lazarow and de lous (12) and the oxidation by coupled mouse liver mitochondria of palmitoylcarnitine was measured as described by Van Hoof ef al. (13). Protein was measured by the method of I owry at al. (14) using bovine serum albumin as standard

Flectron microscopic studies were performed as described by Van Hoof a al. (1.3) for tissue samples without crtochemistry of Van den Branden et al. (15) for cytochemical investigations. For stereological studies, the sections photographed were. in order to

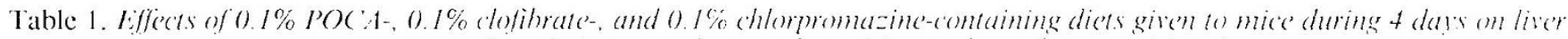
peroxisomal oxidations. eatalase, and carnitine acytransferase' activities*

Carnitine acetyltransferase

Carnitine octanoyltransferase

Carnitine hexanoyltransferase

Carnitine palmitoyltransferase

I actate dehydrogenase

Catalase

Palmitoyl-cos oxidase

l auroyl-Cos oxidase

Cyanide-irsensitive lauroyl-con oxidation

Cilycolate oxidase

Urate oxidase

\section{$0.1 \%$ \\ clefibrate \\ $0.1 \%$ \\ P() ( $A$}

$1.07 \pm 0.26$

$3.18 \pm 0.16$

$3.79 \pm 0.37$

$1.45 \pm 0.12$

$167 \pm 4$

$496) \pm 774$

$4.01 \pm 1.00$

$5.45 \pm 1.12$

$5.1) 6 \pm 1.14$

$0.17 \pm 0.07$

(). $91 \pm 0.14$
$2.79 \pm 0.73$

$11.36 \pm 1.04$

$25.73 \pm 5.20$

$3.68 \pm 0.27$

$12.3 \pm 7$

$9867 \pm 21.84$

$18.08 \pm 2.00$

$30.73 \pm 1.86$

$26.55 \pm 5.20$

(). $30 \pm 0.08$

$0.96 \pm 0.07$
(). $1 \%$

chlorpromazine

$0.27 \pm 0.04$

$1.56 \pm(0.59$

$2.12 \pm 0.26$

$0.99 \pm 0.07$

$1.30 \pm 6$

1792 \pm 178

(0.9) $4 \pm 0.10$

1.4()$\pm 0.17$

$1.07 \pm 0.24$

$0.23 \pm 0.05$

$1.15+0.06$

* Enzyme activities are expressed as $\mu$ mol of substrate consumed or product formed per min and per g of liver. Results are the mean activity \pm Sl:M calculated from at least six animals.

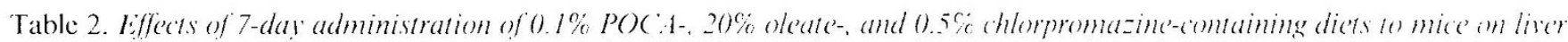
mitoshondrial and peroxisomal oxidations. catalase' and carnitine acyltransferase activitices*

\begin{tabular}{|c|c|c|c|c|}
\hline & Controls & $\begin{array}{l}\text { (). } 1 \% \\
\mathrm{POC} \text { ( } \mathrm{A}\end{array}$ & $\begin{array}{l}20 \% \\
\text { oleate }\end{array}$ & $\frac{0.5 \%}{\text { chlorpromazine }}$ \\
\hline Carnitine acetyltransferase & $1.74 \pm 0.37$ & $15.31 \pm 4.87$ & $4.29 \pm 0.41$ & $2.97 \pm 0 . .35$ \\
\hline Carnitine octanoyltransferase & $10.08 \pm 2.12$ & $6.3 .87 \pm 12.09$ & $27.28 \pm 6.57$ & $27.90 \pm 0.35$ \\
\hline Camitine palmitoyltransferase & $6.21 \pm 0.95$ & $17.20 \pm 2.60$ & $10.72 \pm 1.34$ & $13.81 \pm 1.53$ \\
\hline Butyryl-C"oA dehydrogenase & $9.24 \pm 2.01$ & $9.40 \pm 0.92$ & $7.09 \pm 0.71$ & $6.64 \pm 0.88$ \\
\hline $\begin{array}{l}\text { Mitochondrial palmitoylcarnitine oxi- } \\
\text { dation }\end{array}$ & $0.25 \pm 0.03$ & $0.70 \pm 0.11$ & $0.15 \pm 0.04$ & $0.19 \pm 0.04$ \\
\hline Catalase & $10.73 \pm 1.40$ & $35.00(0 \pm 5.64$ & $12.89 \pm 2.47$ & $10.72 \pm 1.50$ \\
\hline Palmitoyl-( oA oxidase & $4.70 \pm 0.39$ & $84.42 \pm 11.03$ & $24.48 \pm 4.93$ & $24.31 \pm 5.02$ \\
\hline I auroyl-CoA oxidase & $7.24 \pm 1.00$ & $140.3 \pm 18.5$ & $32.52 \pm 5.37$ & $37.14 \pm+. .38$ \\
\hline $\begin{array}{l}\text { Cyanide-insensitive lauroyl-C OA oxida- } \\
\text { tion }\end{array}$ & $6.05 \pm 1.98$ & $109.0 \pm 13.6$ & $27.59 \pm 6.30$ & $30.50 \pm 0.87$ \\
\hline Cilycolate oxidase & $2.51 \pm 0.32$ & $2.72 \pm 0.40$ & $3.28 \pm 0.52$ & $2.81 \pm 0.52$ \\
\hline Urate oxidase & $5.38 \pm 0.40$ & $6.22 \pm 0.83$ & $8.06 \pm 1.31$ & $6.12 \pm 0.67$ \\
\hline Protein (mg/g liver) & $192 \pm 26$ & $167 \pm 15$ & $159 \pm 16$ & $173 \pm 22$ \\
\hline
\end{tabular}

* (atalase reaction exepted ( $\mathrm{J} / \mathrm{mg}$ protein). enzyme activities are expressed as $\mathrm{m} / \mathrm{J} / \mathrm{mg}$ protein. Results are the mean activity \pm Si:M calculated from at least six animals. 
analyse distinct cells, taken from ribbons separated by at least 20 $\mu \mathrm{m}$. The magnification was determined with a grating replica (E. F. Fullam Inc., Schenectady, NY). A multipurpose test grid similar to that described by Weibel et al. (16) was used to calculate the volume fraction or membrane area. For the recording and processing of morphometrical data, an Apple II plus (Apple Computer, Inc. Cupertino, CA) was used.

Very long-chain fatty acids were measured in plasma, each
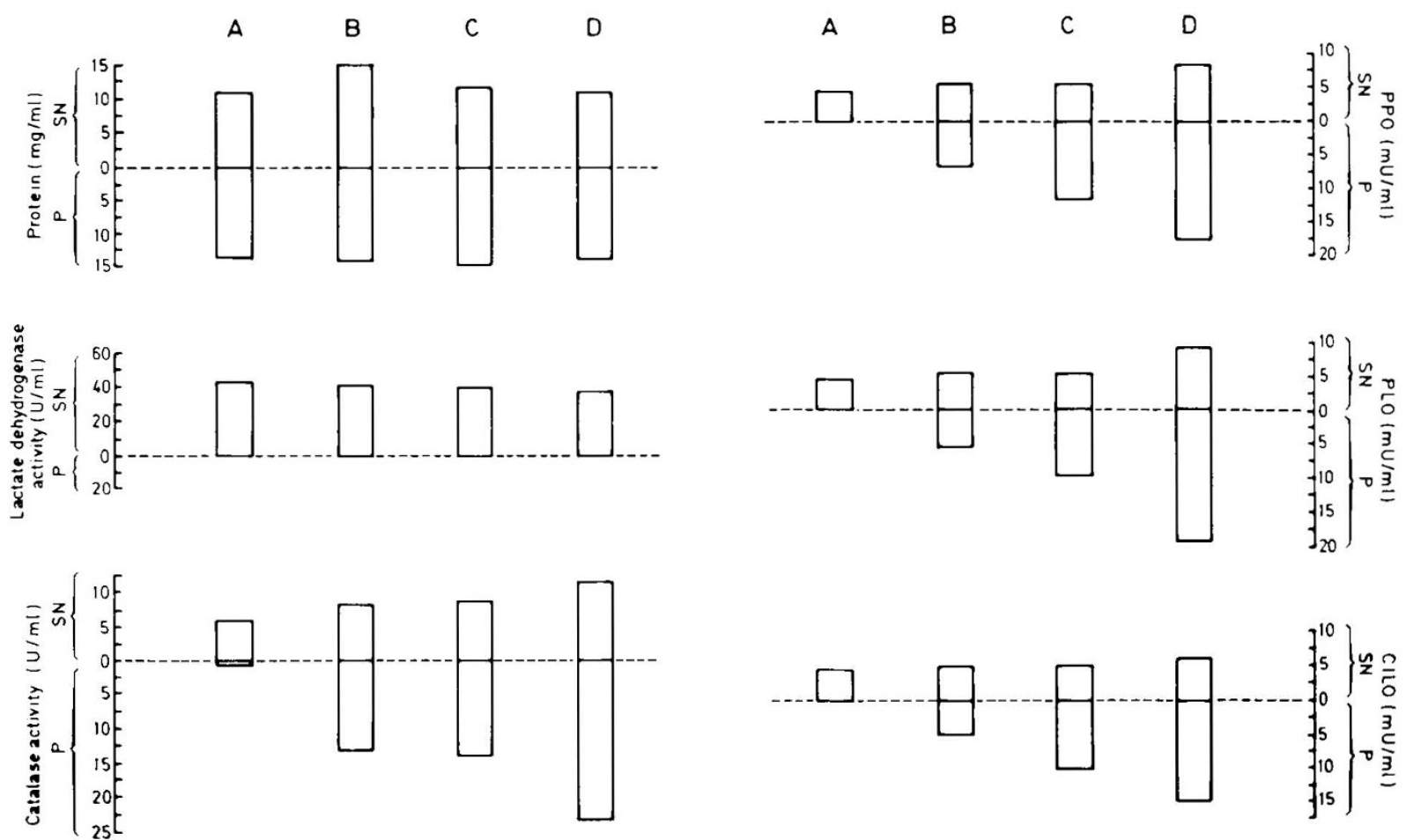

Fig. 2. Effects of various treatments of mice on the activity and sedimentability of heart peroxisomal enzymes. $A$, untreated mice; $B, C$, and $D$, mice receiving 4 days of the $0.1 \%$ POCA, $20 \%$ oleate, and $0.5 \%$ chlorpromazine-containing diets, respectively. The supernatant $(S N)$ and pellet $(P)$ fractions were obtained after high speed centrifugation $(3,000,000 \times g \mathrm{~min})$ of the postnuclear supernatants $(6,000 \times g \mathrm{~min})$ from, in each condition, six pooled myocardia. The values reported in histograms are the means calculated from results of three separate experiments. The enzyme activities are expressed as $\mathrm{nmol}(\mathrm{mU})$ or $\mu \mathrm{mol}(\mathrm{U})$ of substrate consumed or product formed per min per ml of fraction. Each (SN or P) fraction corresponds to $200 \mathrm{mg}$ of myocardium/ml. $P P O$, peroxisomal palmitoyl-CoA oxidase $\left(\mathrm{H}_{2} \mathrm{O}_{2}\right.$ production); $P L O$, peroxisomal lauroyl- $\mathrm{CoA}$ oxidase $\left(\mathrm{H}_{2} \mathrm{O}_{2}\right.$ production); $C I L O$, cyanide-insensitive lauroyl-CoA oxidation (NADH production).

Table 3. Quantitative ultrastructural analysis of mouse liver hepatocytes*

\begin{tabular}{|c|c|c|c|c|}
\hline & Controls & $\begin{array}{l}0.1 \% \\
\text { POCA }\end{array}$ & $\begin{array}{l}20 \% \\
\text { oleate }\end{array}$ & $\begin{array}{c}0.5 \% \\
\text { chlorpromazine }\end{array}$ \\
\hline \multicolumn{5}{|c|}{$\begin{array}{l}\text { Fractional volume (\% of cytoplasmic } \\
\text { volume) }\end{array}$} \\
\hline Peroxisomes & $1.41 \pm 0.12$ & $3.87 \pm 0.41$ & $2.35 \pm 0.29$ & $2.51 \pm 0.30$ \\
\hline Lipid droplets & $0.29 \pm 0.15$ & $3.28 \pm 0.92$ & $1.57 \pm 0.61$ & $1.90 \pm 0.26$ \\
\hline Mitochondria & $19.50 \pm 0.93$ & $18.53 \pm 1.13$ & $18.29 \pm 1.07$ & $15.95 \pm 0.76$ \\
\hline \multicolumn{5}{|c|}{ External surface $\left(\mu \mathrm{m}^{2} / \mu \mathrm{m}^{3}\right)$} \\
\hline Peroxisomes & $0.118 \pm 0.012$ & $0.369 \pm 0.035$ & $0.188 \pm 0.028$ & $0.313 \pm 0.042$ \\
\hline Lipid droplets & $0.024 \pm 0.009$ & $0.081 \pm 0.015$ & $0.136 \pm 0.075$ & $0.153 \pm 0.024$ \\
\hline Mitochondria & $1.241 \pm 0.081$ & $1.037 \pm 0.056$ & $0.984 \pm 0.095$ & $0.971 \pm 0.043$ \\
\hline \multicolumn{5}{|l|}{ Feature $/ \mu \mathrm{m}^{2}$} \\
\hline Peroxisomes & $0.063 \pm 0.006$ & $0.192 \pm 0.019$ & $0.121 \pm 0.017$ & $0.232 \pm 0.035$ \\
\hline Lipid droplets & $0.010 \pm 0.004$ & $0.022 \pm 0.004$ & $0.019 \pm 0.007$ & $0.085 \pm 0.010$ \\
\hline Mitochondria & $0.495 \pm 0.025$ & $0.436 \pm 0.035$ & $0.377 \pm 0.027$ & $0.375 \pm 0.020$ \\
\hline \multicolumn{5}{|l|}{ Particles $/ \mu \mathrm{m}^{3}$} \\
\hline Peroxisomes & 0.097 & 0.308 & 0.198 & 0.514 \\
\hline
\end{tabular}

* The analyzed section area was $1357,1460,1430$, and $1453 \mu \mathrm{m}^{2}$ for control, $0.1 \%$ POCA, $20 \%$ oleate, and $0.5 \%$ chlorpromazine treatments, respectively. Values are given \pm SEM for analyzed sample. The estimation of particles numbers is obtained by application of the equation: $N_{v}=$ $\left(N_{a}\right)^{3 / 2} / \beta\left(V_{v}\right)^{1 / 2},(16)$, where $N_{v}$ is the number of particles per unit volume, $N_{a}$ is the number of profiles per unit area in section, $V_{v}$ is the volume fraction of particles, and $\beta$ is a shape factor. Peroxisomes are considered as spheres $(\beta=1.382)$ and their population is considered homogeneous in size. 
experimental group consisting of at least four animals. Their extraction was performed as described by Folch ot al. (17) after addition of $2 \mu \mathrm{g}$ of heptacosanoic acid as internal standard and before transmethylation with $\mathrm{HCl} 2 \mathrm{~N}$ in methanol at $75^{\circ} \mathrm{C}$ for $16 \mathrm{~h}$. The gas chromatographic identification of methylesters was made by comparison of the retention times with those of known standards.

\section{RISUITS}

Biochemical Studies. In vitro Inhithition by ('hlorpromazine of Several Enzinc Activities. The inhibitory effect of chlorpromarine on the activity of the total mitochondrial carnitine palmitoyltransferase from mouse heart and liver is illustrated in Figure 1. In this experiment the liver enzyme activity in the presence of $1 \mathrm{mM}$ chlorpromazine amounted to 0.07 (control values 1.16) $\mathrm{U} / \mathrm{g}$ tissue. The heart enzyme reaction was completely prevented by this concentration of the phenothiazinc. Analogs including lluphenazine. clopenthixol, and trifluoperazine also inhibited both liver and heart carnitine palmitoyltransferases. In both organs. higher to lower inhibitions were respectively achieved by chlorpromazine, trifluoperazine. clopenthixol. and fluphenazine (not shown). Mouse liver and heart cytochrome coxidase activities were similarly inhibited by chlorpromazine and could not be detected in the presence of more than $0.8 \mathrm{mM}$ chlorpromazine. The strongest inhibition was obtained under clopenthixol: $0.15 \mathrm{mM}$ clopenthixol induced complete inhibition of cytochrome c oxidase activity from liver or heart. Peroxisomal carnitine octanoyltransferase was inhibited by phenothiazines in these mouse tissues (data not shown) as previously reported for rat liver (2).

The (). $1 \%$ (hlorproma-inc-(ontaining I)ict. Administration of a $0.1 \%$ chlorpromazine-containing diet for 1 wh had little or no
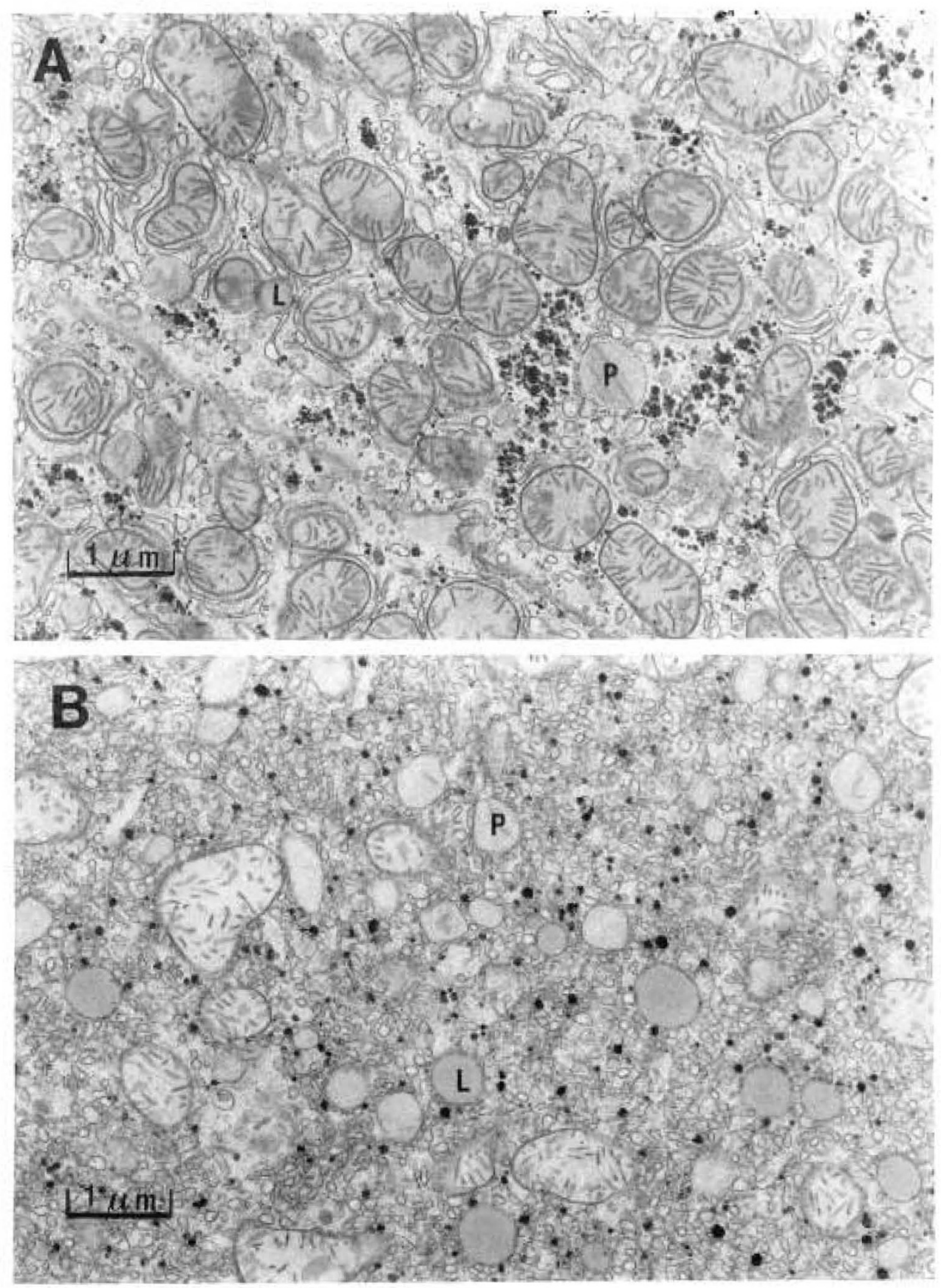

Fig. 3. Peroxisomal proliferation in hepatocytes from the $0.5 \%$ chlorpromazine-treated mice. $L$. lipid droplets: $P$. peroxisomes. 1 . control mouse liver $(1 \mu \mathrm{m})$. B. chlorpromazine-treated mousc liver, $0.5 \%(1 \mu \mathrm{m})$. 
effect on liver peroxisomal $\beta$-oxidation, catalase, or carnitine acyltransferase activities (Table 1). Prolonged treatment with $0.1 \%$ chlorpromazine (1 month) did not further modify these enzyme activities (not shown). By contrast, in livers from animals given the $0.1 \%$ clofibrate or $0.1 \%$ POCA-containing diet for 1 wk, an enhanced capacity of peroxisomal $\beta$-oxidation as well as increased carnitine acyltransferase activities were measured ( $\mathrm{Ta}-$ ble 1). The administration of $0.1 \%$ chlorpromazine-containing diet failed to increase the activity of the peroxisomal $\beta$-oxidation in heart (not shown).

Administration to Mice of a $0.5 \%$ Chlorpromazine-Containing
Diet. The higher dose of chlorpromazine was effective after 4 days in producing increased liver peroxisomal $\beta$-oxidizing capacity and proliferation of hepatic peroxisomes (see below). The effects of this treatment on liver enzymology were less pronounced than those obtained under $0.1 \%$ POCA treatment and of the same magnitude as those found after a high fat diet (Table 2). The hepatic enzymes were affected differently by the treatments and, in livers from the $0.5 \%$ chlorpromazine-treated mice, the activities of palmitoyl-CoA oxidase, lauroyl-CoA oxidase, and cyanide-insensitive lauroyl-CoA oxidation were increased 5fold; those of carnitine acyltransferases were approximately 2-
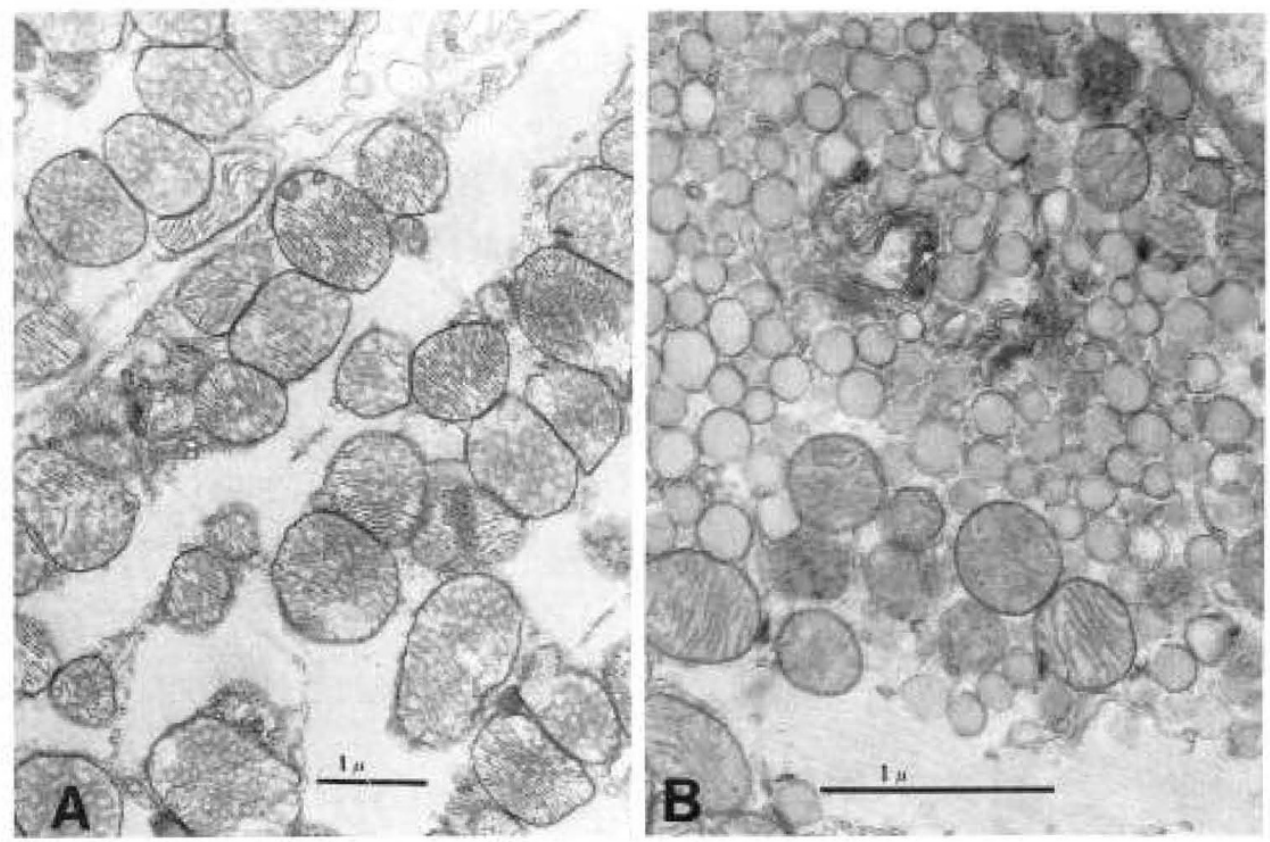

Fig. 4. Comparison between cardiomyocytes from control $(A)$ and $0.5 \%$ chlorpromazine-treated $(B)$ mice. Note the massive organelle proliferation characterizing the heart cell from the treated animal.
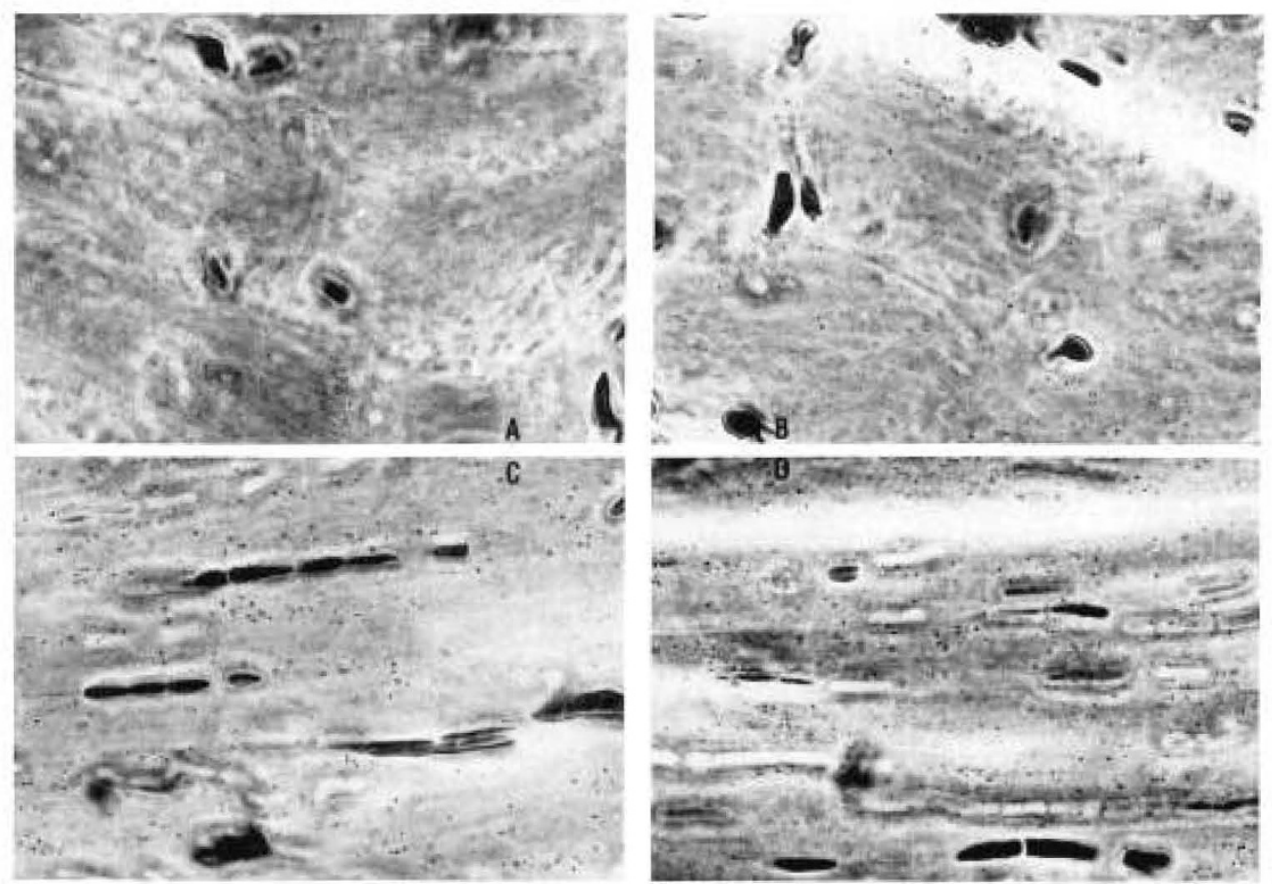

Fig. 5. Comparison between the peroxisomal proliferations induced by various treatments in myocardium. Peroxisomes are recognised by their positive response (black labeling) to the $\mathrm{DAB}$ reaction. $A$, untreated mice; $B, 0.1 \%$ POCA-treated mice; $C, 20 \%$ oleate-treated mice; $D, 0.5 \%$ chlorpromazine-treated mice. 
fold higher, while catalase, glycolate oxidase. urate oxidase. and butyryl-(o $\wedge$ dehydrogenase activities as well as mitochondrial palmitoylearnitine oxidation were normal or decreased (Table 2).

Heart peroxisomal induction was minimal in mice receiving POCA and optimal in the animal given $0.5 \%$ chlorpromazine or high fat diets. Biochemical changes characterizing the peroxisomal proliferation in the heart were the enhancement of earnitine octanoyltransferase (not shown), catalase and peroxisomal $\beta$ oxidizing activities, and a higher proportion of these activities linked to sedimentables particles (Fig. 2).

Morphological studies. The peroxisomal population was studied by light and electron microscopy in liver and heart from $0.1 \%$ POCA - $20 \%$ oleate- 0.1 and $0.5 \%$ chlorpromazine-treated mice and compared with controls. During the administration of the $0.1 \%$ chlorpromazine-containing diet an abnormal occurrence of lipid droplets was observed in liver cytosol but no significant change was induced at the level of peroxisomal population in liver and heart.

Lipid Droplet.s. In hepatocytes from animals receiving the $0.5 \%$ chlorpromazine-containing diet, the number of lipid droplets was increased relative to the control liver cells while a peculiar aspect of the smooth endoplasmic reticulum was noticed. The accumulation of lipid droplets was also observed in hepatocytes from $0.1 \%$ POC $\triangle$ - and $20 \%$ oleate-treated mice. The characteristics of this abnormal accumulation of lipid droplets are given in Table 3. (onversely to liver. no abnormal accumulation of lipid droplets was seen in cardiac cells from treated animals.

Peroxisomal Proliferation. Peroxisomes were increased in size and number in hepatocytes from treated animals (Table 3). The increase of the peroxisomal volume fraction was maximal after POCA. By contrast with peroxisomes, little or no change in the mitochondrial population could be recorded. The ratio between the peroxisomal and the mitochondrial volume fractions were equal to $0.07,0.21,0.13$, and 0.16 in livers from the control, the $0.1 \%$ POCA-, 20\% oleate- and $0.5 \%$ chlorpromarine-treated animals, respectively. The ratio between the peroxisomal and the mitochondrial envelope surfaces also was increased after treatment (lable 3). Figure 3 illustrates the peroxisomal proliferation in liver from mice given the $0.5 \%$ chlorpromazine treatment.

In myocardial cells, increased numbers of microbodies were observed 4 days after the onset of the treatments of mice with the $0.1 \% P(O(\wedge-.20 \%$ oleate- and $0.5 \%$ chlorpromazine-containing diets (Fig. 4). The peroxisomal nature of these cellular structures was strongly supported by their cytochemical reaction for catalase. Maximal peroxisome proliferation in heart cells was obtained after administration of oleate and chlorpromazine while POCA treatment was less efficient (Fig. 5).

I.amellar. Structures. The 0.1 and $0.5 \%$ chlorpromazine treatments resulted in the abnormal occurrence of lamellar structures in the liver cytosol (Fig. 6). The latter material was more frequently seen in the animals receiving the lower dose of chlorpromazine. It is similar to that observed in cytosol or in lysosomes from liver or other tissues of patients suffering from peroxisomal deficiency syndromes (Fig. 6) and is classically believed to represent very long-chain fatty acid deposition $(18-22)$. In the $(0.1 \%$ chlorpromazine-treated animals, the deficient oxidation of very long-chain fatty acids was confirmed by their accumulation in plasma; the $C_{20} / C_{22}$ ratio [ratio between cerotic $\left(C_{26}\right)$ and behenic $\left(C_{22}\right)$ acids] was increased 2- 10.3 -fold (23).

\section{DISCUSSION}

Changes induced in liver. Peroxisomal proliferation in liver from rodents in a variety of conditions has been documented extensively $(12,24)$. In most cases it consists of the enhancement of both peroxisomal $\beta$-oxidizing activities and peroxisomal volume fractions. In addition to the peroxisomal changes. increased ability of mitochondria to oxidize fatty acids also has been reported (25-27). Diets containing $0.1 \%$ POCA. $20 \%$ oleate. and most probably $0.5 \%$ chlorpromazine lead to the inhibition or chronic overloading of mitochondrial fatte acid oxidation. Induction of peroxisomal proliferation is a common characteristic of these animal models.

In the animals receiving a $0.1 \%$, chlorpromazine-containing diet. no peroxisomal proliferation occurs. In this case, the peroxisomal fatty acid oxidation is impaired in rive as attested by the deficient oxidation of very long-chain fatty acids. I amellar structures that are similar to the inclusions in the cercbrohepatorenal syndrome (Zellweger disease) and inlantile Refsum disease livers and in adrenoleukodystrophy brain are observed in hepatocytes from $0.5 \%$ chlorpromazine-treated animals and compared with lamellar structures in a patient with deficient acyl-COA oxidase. These structures are believed to be elicited by the well-known storage of very long-chain fatty acids in these diseases $(18,28)$. The shortening of very long-chain substrates has been demonstrated to be catalyed by the peroxisomes (29). 31). Multilamellar structures also have been described in lysosomes from tissues exposed to cationic amphiphilic drugs that inhibit lysosomal phospholipid degradation (32-34). In our experiments, the increase of very long-chain fatty acids in plasma supports the idea that lamellar structures represent very long-
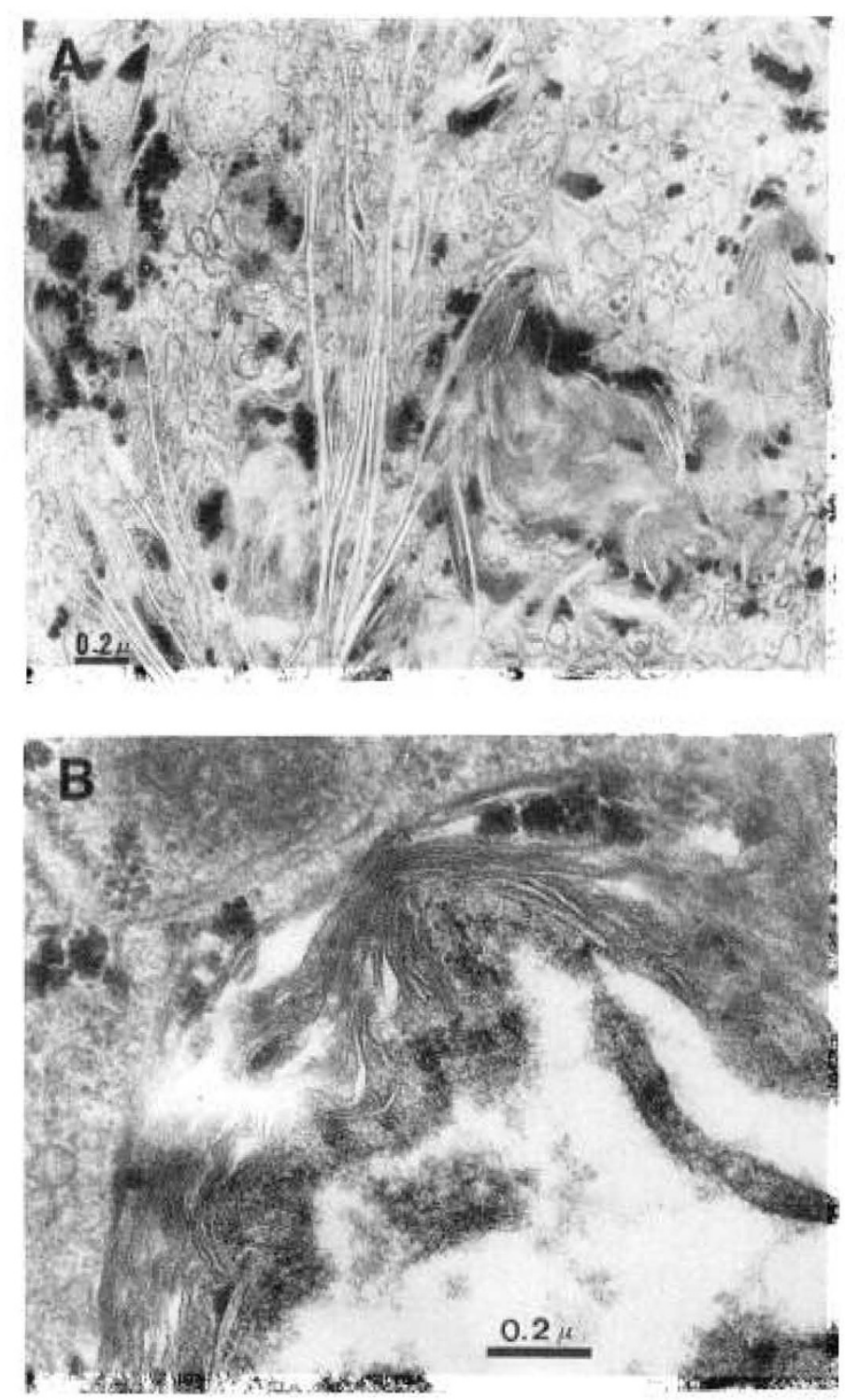

Fig. 6. Lamellar structures seen in liver cytosol from a $0.1 \%$ chlorpromazine-treated mouse $(.1)$ and from a patient with the acyloc oxidase defieiency $(B)$. 
chain fatty acid deposition consecutive to the inhibition (in vivo) of peroxisomal fatty acid oxidation. Both mechanisms (deficient phospholipid degradation and peroxisomal fatty acid oxidation) may operate simultaneously in the genesis of the lamellar structures in chlorpromazine-treated mouse livers.

The mouse liver carnitine acyltransferases are inhibited by chlorpromazine and are not inactivated by the phenothiazine. Indeed, the activity of these enzymes measured on liver homogenates are normal and increased in mice given the 0.1 and $0.5 \%$ chlorpromazine-containing diets, respectively.

Peroxisomal proliferation also takes place in the myocardium. Both biochemical and cytochemical aspects of heart peroxisomal induction have been studied in previous works. In rodents, peroxisomal $\beta$-oxidation activity has been measured in the heart $(35,36)$ as well as its enhancement when partially hydrogenated fish oil or soybean oil are included in the diet (37). The morphological description of heart peroxisomes in rodents, but also in primates, has been given previously (38). Fahimi et al. (39) have demonstrated that ethanol in the diet was efficient enough in rats to increase myocardial catalase activity and the number of heart DAB-reactive organelles. The increase of heart peroxisomes has also been described in mice given phytol (15). With the present work, we demonstrate the parallelism that exists between the number of DAB-positive organelles and the activity and sedimentability of catalase and peroxisomal $\beta$-oxidation. As was suggested for liver, the propensity of the treatments to induce peroxisomal proliferation in the heart might be correlated to their ability to depress mitochondrial fatty acid oxidation in this tissue.

Acknowledgments. Professor François Van Hoof is gratefully acknowledged. We thank Professor G. Dacremont (Gent) for the assay of very long-chain fatty acids. The biopsies of the patient with acyl-CoA oxidase deficiency was made available by Dr. J. Scotto, Dr. B. T. Poll-Thé, and Dr. J. M. Saudubray (Paris). The authors are endebted to Than-Tuyn Müller, Annette MarcelisHerssens, and Bernadette Wantier. Marina Pauwels prepared the cytochemical stains for light and electron microscopy.

\section{REFERENCES}

1. Leighton F, Pérsico R, Necochea C 1984 Peroxisomal fatty acid oxidation is selectively inhibited by phenothiazines in isolated hepatocytes. Biochem Biophys Res Commun 120:505-511

2. Vamecq J 1987 Chlorpromazine and carnitine-dependency of rat liver peroxisomal $\beta$-oxidation of long chain fatty acids. Biochem J 241:783-791

3. Sherratt HSA, Bartlett K, Bone AJ, Koundakjian PP, Turnbull DM, Osmundsen H, Van Hoof F 1982 Hepatic peroxisomal proliferation caused by ethyl 2(5(4-chloro-phenyl)pentyl)oxiran-2-carboxylate (CPOC): a hypoglycemic inhibitor of mitochondrial fatty acid oxidation. Ann NY Acad Sci 386:446448

4. Horie $\mathrm{S}$, Suga $\mathrm{T} 1985$ Enhancement of peroxisomal $\beta$-oxidation in the liver of rats and mice treated with valproic acid. Biochem Pharmacol 34:1357-1362

5. Draye J-P, Vamecq J 1987 The inhibition by valproic acid of the mitochondrial oxidation of monocarboxylic and $\omega$-hydroxymonocarboxylic acids: possible implications for the metabolism of gamma aminobutyric acid. J Biochem (Tokyo) 102:235-242

6. Price SC, Hall DE, Hinton RH 1985 Does lipid accumulation in rodent liver necessarily lead to peroxisome proliferation. Biochem Soc Trans 13:153 154

7. Vamecq J, Van Hoof F 1984 Implication of a peroxisomal enzyme in the catabolism of glutaryl-CoA. Biochem J 221:203-211

8. Miyazawa S, Ozasa H, Osumi T, Hashimoto T 1983 Purification and properties of carnitine octanoyltransferase and carnitine palmitoyltransferase from rat liver. J Biochem (Tokyo) 94:529-542

9. de Duve C, Pressman BC, Gianetto R, Wattiaux R, Appelmans F 1955 Tissue fractionation studies. 6 . Intracellular distribution patterns of enzymes in rat liver tissue. Biochem J 60:604-617

10. Baudhuin P, Beaufay H, Rahman-Li Y, Sellinger OZ, Wattiaux R, Jacques $\mathrm{P}$, de Duve $C 1984$ Tissue fractionation studies. 17. Intracellular distribution of monoamine oxidase, aspartate aminotransferase, alanine aminotransferase, D-amino-acid oxidase and catalase in rat liver tissue. Biochem $\mathbf{J}$ 92:179-184
11. Ikeda Y, Dabrowski C, Tanaka K 1983 Separation and properties of five distinct acyl-CoA dehydrogenases from rat liver mitochondria. J Biol Chem 258:1066-1076

12. Lazarow PB, de Duve C 1976 A fatty acyl-CoA oxidizing system in rat liver peroxisomes; enhancement by clofibrate, a hypolipidemic drug. Proc Natl Acad Sci USA 73:2043-2046

13. Van Hoof F, Hue L, Vamecq J, Sherratt HSA 1985 Protection of rats by clofibrate against the hypoglycaemic and toxic effects of hypoglycin and pent-4-enoate. An ultrastructural and biochemical study. Biochem J 229:387-397

14. Lowry OH, Rosenbrough NJ, Farr HL, Randall RJ 1951 Protein measurement with folin phenol reagent. J Biol Chem 193:265-275

15. Van den Branden C, Vamecq J, Wibo I, Roels F 1986 Phytol and peroxisome proliferation. Pediatr Res 20:411-415

16. Weibel E. R, Stäubli W, Gnägi HR, Hess FA 1969 Correlated morphometric and biochemical studies on the liver cell. I. Morphometric model, stereologic methods, and normal morphometric data for rat liver. J Cell Biol 42:68-91

17. Folch J, Lees M, Sloane Stanley G H 1957 A simple method for the isolation and purification of total lipides from animals tissues J Biol Chem 226:497509

18. Igarashi M, Schaumburg HH, Powers JM, Kishimoto Y, Kolodny E, Suzoki K 1976 Fatty acid abnormality in adrenoleukodystrophy. J Neurochem 26:851-860

19. Menkes JH, Corbo LM 1977 Adrenoleukodystrophy. Accumulation of cholesterol esters with very long chain fatty acids. Neurology 27:928-932

20. Powers JM, Schaumburg HH, Johnson AB, Raine CS 1980 A correlative study of the adrenal cortex in adrenoleukodystrophy: evidence for a fatal intoxication with very long chain satured fatty acids. Enzyme cytochemistry, fine structure, tissue culture, proposed molecular model and cellular pathogenesis. Invest Cell Pathol 3:353-376

21. Kerckaert I, Dingemans KP, Heymans HSA, Vamecq J, Poll-Thé BT, Van den Branden C, Roels F 1986 Polarizing inclusions in the liver of children with congenital peroxisomal diseases. Eur J Cell Biol 41(suppl 14): 22

22. Roels F, Cornelis A, Poll-Thé BT, Aubourg P, Ogier H, Scotto GM, Saudubray JM 1986 Hepatic peroxisomes are deficient in infantile Refsum disease: a cytochemical study of 4 cases. Am J Med Genet 25:257-271

23. Van den Branden C, Vamecq J, Dacremont G, Premereur N, Roels F 1987 Short and long term influence of phenothiazine administration on liver peroxisomal fatty acid oxidation in rodents. FEBS Lett 222:21-26

24. Goldfischer S, Reddy JK 1984 Peroxisomes (microbodies) in cell pathology. Int Rev Exp Pathol 26:45-84

25. Mannaerts GP, Thomas J, Debeer LJ, McGarry JD, Foster DW 1978 Hepatic fatty acid oxidation and ketogenesis after clofibrate treatment. Biochim Biophys Acta 529:201-211

26. Mannaerts GP, Debeer LJ, Thomas J, De Schepper PJ 1979 Mitochondrial and peroxisomal fatty acid oxidation in liver homogenates from control and clofibrate-treated rats. J Biol Chem 254:8841-8846

27. Capuzzi DM, Intenzo CM, Lackman RD, Whereat AF, Scott DM 1983 Stimulation of fatty acid utilization by sodium clofibrate in rat and monkey hepatocytes. Biochem Pharmacol 32:2195-2203

28. Johnson AB, Schaumburg HH, Powers JM 1976 Histochemical characteristics of the striated inclusions of adrenoleukodystrophy. J Histochem Cytochem 24:725-730

29. Kawamura N, Moser HW, Kishimoto Y 1981 Very long-chain fatty acid oxidation in the rat liver. Biochem Biophys Res Commun 99:1216-1225

30. Singh I, Moser HW, Moser AE, Kishimoto Y 1981 Adrenoleukodystrophy: impaired oxidation of long chain fatty acids in cultured skin fibroblasts and adrenal cortex. Biochem Biophys Res Commun 102:1223-1229

31. Singh I, Moser AE, Goldfischer S, Moser HW 1984 Lignoceric acid is oxidized in the peroxisome: implications for the Zellweger cerebro-hepato-renal syndrome and adrenoleukodystrophy. Proc Natl Acad Sci USA 81:4203-4207

32. Lüllmann H, Lüllmann-Rauch R, Wasserman O 1978 Lipidosis induced by amphiphilic cationic drug. Biochem Pharmacol 27:1103-1108

33. Matsuzawa Y, Hostettler KY 1980 Inhibition of lysosomal phospholipase A and phospholipase $\mathrm{C}$ by chloroquine and $4,4^{\prime}-\mathrm{Bis}$ (diethylaminoethoxy) $\alpha, \beta$ diethyldiphenylethane. J Biol Chem 255:5190-5194

34. Fauster R, Honegger U, Wiesmann U 1983 Inhibition of phospholipid degradation and changes of the phospholipid-pattern by desipramine in cultured human fibroblasts. Biochem Pharmacol 32:1737-1744

35. Connock MJ, Perry SR 1983 Detection of acyl-COA $\beta$-oxidation enzymes in peroxisomes (microperoxisomes) of mouse heart. Biochem Int 6:545-551

36. Van Veldhoven P, Mannaerts GP 1985 Comparison of the activities of some peroxisomal and extra peroxisomal lipid-metabolizing enzymes in liver and extrahepatic tissues of the rat. Biochem J 227:737-741

37. Norseth J, Thomassen MS 1983 Stimulation of microperoxisomal $\beta$-oxidation in rat heart by high fat diets. Biophys Biochim Acta 75:312-320

38. Hicks L, Fahimi HD 1977 Peroxisomes (microbodies) in the myocardium of rodents and primates. A comparative ultrastructural cytochemical study. Cell Tissue Res 175:467-481

39. Fahimi HD, Kino M, Hicks L, Thorp KA, Abelman WH 1979 Increased myocardial catalase in rat fed ethanol. Am J Pathol 96:376 -386 